Laporan Penelitian

\title{
Gangguan pendengaran penderita Tuberkulosis Multidrug Resistant
}

\author{
Yulianti, Sally Mahdiani \\ Departemen Telinga Hidung Tenggorok - Bedah Kepala Leher \\ Fakultas Kedokteran Universitas Padjadjaran/Rumah Sakit Dr. Hasan Sadikin \\ Bandung
}

\begin{abstract}
ABSTRAK
Latar belakang: Tuberkulosis Multidrug Resistant (TB MDR) merupakan penyakit tuberkulosis (TB) yang resisten terhadap isoniazid dan rifampisin, dengan atau tanpa resisten terhadap obat antiTB lain. Terapi aminoglikosida pada TB MDR berisiko untuk terjadinya gangguan fungsi telinga dan sistem keseimbangan tubuh, yang dapat bersifat irreversible atau permanen. Kerusakan pada koklea dapat menimbulkan penurunan pendengaran permanen. Tujuan: Mengetahui gangguan pendengaran penderita TB MDR di poliklinik TB MDR Ilmu Penyakit Dalam RS Hasan Sadikin Bandung. Metode: Penelitian deskriptif secara retrospektif pada pasien TB MDR yang berobat jalan di poliklinik TB MDR Ilmu Penyakit Dalam Rumah Sakit Hasan Sadikin Bandung periode 1 Januari - 31 Desember 2013. Hasil: Didapatkan gangguan pendengaran sebanyak 20,8\% dari pasien TB MDR selama mendapat terapi TB MDR dengan keluhan tinitus dan gangguan pendengaran dengan onset timbulnya keluhan di bulan ke-3 (53,3\%), kemudian bulan ke-6 (40\%), dan bulan ke-10 (6,7\%) setelah mulai pemberian terapi TB MDR. Pada pemeriksaan audiometri nada murni ditemukan penurunan pendengaran sensorineural yang bervariasi dari derajat ringan sampai berat. Kesimpulan: Pengobatan TB MDR dapat menyebabkan penurunan pendengaran sensorineural.
\end{abstract}

Kata Kunci : Tuberkulosis Multidrug Resistant, audiometri nada murni, gangguan pendengaran sensorineural

\begin{abstract}
Background: Multidrug Resistant Tuberculosis (MDR TB) is a tuberculosis (TB) which resistant to isoniazid and rifampin, with or without resistancy to other anti-TB drugs. Aminoglycoside therapy in MDR $T B$ patients takes risks to malfunctioning of the ear and balance system. The hearing loss and balance system impairment that appeared are irreversible/permanent. Cochlear damage can cause permanent hearing loss. Purpose: To describe hearing loss in patients with MDR TB at MDR TB clinic of internal medicine in Hasan Sadikin hospital. Methods: A retrospective descriptive study on MDR TB patients in MDR TB outpatient clinic of Internal Medicine in Hasan Sadikin hospital in the period of January $1^{\text {st }}$ to December 31 th 2013. Results: There were 20,8\% of MDR TB patients who received treatment for $M D R T B$ with tinnitus and hearing loss with onset of presentation at the $3^{\text {rd }}$ month $(53,3 \%)$, at the $6^{\text {th }}$ month $(40 \%)$, and at the $10^{\text {th }}$ month $(6,7 \%)$ of MDR TB therapy. Pure tone audiometry examination found sensorineural hearing loss with various degrees from mild to severe. Conclusion: Treatment of MDR TB could cause sensorineural hearing loss.
\end{abstract}

Keywords: Tuberculosis Multidrug Resistant, pure tone audiometric, sensorineural hearing loss

Alamat korespondensi : dr. Yulianti. Kontak : 08122375075. Email : yulie_fn@yahoo.com Departemen THT-KL FK UNPAD/RSHS Bandung. Jl. Pasteur No. 38 Bandūng. 


\section{PENDAHULUAN}

Tuberkulosis (TB) merupakan salah satu penyakit penyebab kematian di dunia khususnya di Asia dan Afrika. Sejak tahun 2005, ditandai adanya peningkatan prevalensi yang bisa disebabkan oleh pertumbuhan populasi di India, Cina, Indonesia, Afrika Selatan, dan Nigeria. Menurut World Health Organization (WHO), prevalensi kasus TB tahun 2011 terdapat 8,7 juta kasus. TB Multidrug Resistant (TB MDR) ditemukan sebanyak 0,5 juta kasus dengan 60.000 kasus baru. Prevalensi TB di Indonesia pada tahun 2011 adalah 281 per 100.000 penduduk dengan angka kematian 27 per 100.000 penduduk. Kasus baru TB MDR di Indonesia sebanyak 1,9\% dan TB MDR yang berasal dari kasus TB yang telah diobati didapatkan $12 \%{ }^{1}$

TB MDR didefinisikan sebagai penyakit tuberkulosis yang resisten terhadap isoniazid dan rifampisin, dengan atau tanpa resisten terhadap obat anti-TB lain. Oleh karena itu, tergantung pada pola kerentanan individu, sisa obat oral lini pertama harus tepat dikombinasikan dengan tambahan obat lini kedua yang terdiri dari aminoglikosida injeksi (amikasin, kanamisin, kapreomisin), fluoroquinolone (siprofloksasin, ofloksasin, levofloksasin, moksifloksasin), anti-TB bakteriostatik lini kedua (etionamid, protionamide, sikloserine, asam salisilat paraamino, thiocetazone), dan anti tuberkulosis lainnya (klofazimin, amoksisilin atau amoksisilin klavulanat, klaritromisin, linezolid). ${ }^{2}$

Munculnya resistensi terhadap anti tuberkulosis khususnya pada TB MDR telah menjadi hambatan serius untuk pengendalian TB global. Pengobatan yang tidak optimal dan penyebaran tuberkulosis yang berlanjut di masyarakat sebenarnya merupakan masalah yang paling penting dalam perkembangannya dan dapat dicegah. ${ }^{3}$
Pengobatan pasien TB MDR terdiri atas 2 (dua) tahap yaitu tahap awal dan tahap lanjutan. Pengobatan TB MDR memerlukan waktu yang lebih lama daripada pengobatan pasien TB bukan MDR, yaitu sekitar 18-24 bulan. Pada tahap awal pasien akan mendapat Obat Anti Tuberkulosis (OAT) lini kedua minimal 4 jenis OAT yang masih sensitif. Salah satunya adalah OAT injeksi, yaitu kanamisin. Pada tahap lanjutan semua OAT lini kedua yang dipakai pada tahap awal dilanjutkan kecuali OAT injeksi. Pasien TB MDR memerlukan pengobatan yang lebih kompleks, yaitu menggunakan OAT yang efek sampingnya lebih banyak. ${ }^{4}$

Sebuah isu penting yang berkaitan dengan pemberian jangka panjang pengobatan injeksi adalah toksisitas. Ototoksisitas dan nefrotoksisitas diakui sebagai efek samping yang berhubungan dengan dosis aminoglikosida. Ototoksisitas dan nefrotoksisitas menjadi perhatian utama karena rentang terapeutik yang sempit dan variabilitas farmakokinetik yang luas antara pasien. $^{3}$

Obat ototoksik didefinisikan sebagai obat yang mempunyai potensi menimbulkan reaksi toksik pada struktur-struktur di telinga dalam seperti koklea, vestibulum, kanalis semisirkularis, dan otolith. Kerusakan pada struktur-struktur ini dapat memberikan gejala berupa gangguan pendengaran, tinitus, dan gangguan keseimbangan. Ototoksisitas didefinisikan sebagai kerusakan pada struktur koklea dan atau vestibuler di telinga akibat paparan zat kimia. ${ }^{5}$

Kerusakan pada telinga dalam yang disebabkan oleh penggunaan obat tertentu seringkali ditemukan dalam praktik kedokteran sehari-hari. Penggunaan obat di negara berkembang seperti aminoglikosida seringkali digunakan untuk pengobatan pneumonia, diare, dan tuberkulosis paru. Didapatkan angka kejadian ototoksisitas yang tinggi akibat pemakaian obat tersebut di atas. ${ }^{6}$ 
Efek samping nefrotoksisitas biasanya bersifat reversible sedangkan ototoksisitas bersifat permanen karena disebabkan oleh adanya kematian sel-sel rambut luar pada organ Corti dan sel sensorik tipe I pada organ vestibular. ${ }^{7}$

Paparan awal obat ototoksik biasanya memengaruhi daerah basal koklea. Paparan lanjutan menyebabkan penyebaran kerusakan ke arah apeks. Seiring meningkatnya tingkat kerusakan pada sel rambut luar, perubahan degeneratif ikut terlibat dan dapat memengaruhi sel rambut dalam. Berbagai derajat atrofi pada stria vaskularis dapat terlihat berhubungan dengan perubahan sel rambut. $^{8}$

Meskipun penggunaan aminoglikosida tidak bisa dihentikan pada individu dengan TB MDR, ada strategi yang dapat dilakukan untuk mengurangi tingkat gangguan pendengaran pada pasien tersebut yaitu dengan melakukan suatu monitoring fungsi pendengaran. Deteksi dini gangguan pendengaran akibat obat ototoksik memberikan kesempatan kepada para dokter untuk mengevaluasi pemberian terapi dalam meminimalkan atau mencegah gangguan pendengaran yang membutuhkan rehabilitasi. ${ }^{3}$

Atas dasar pertimbangan tersebut penulis tertarik untuk mengetahui gambaran gangguan pendengaran yang terjadi pada penderita TB MDR di poliklinik TB MDR Ilmu Penyakit Dalam RS Hasan Sadikin Bandung.

\section{METODE}

Pada penelitian ini dilakukan penelitian deskriptif secara retrospektif pada pasien Tuberkulosis Multidrug Resistant (TB MDR) yang berobat jalan di poliklinik TB MDR Ilmu Penyakit Dalam Rumah Sakit Hasan Sadikin Bandung, pada periode 1 Januari - 31 Desember 2013. K r i t e ri a inklusi yang digunakan pada penelitian ini adalah penderita TB MDR yang mendapat pengobatan kanamisin. Sedangkan kriteria eksklusinya adalah pasien mempunyai riwayat otitis media, perforasi membran timpani, kelainan kongenital pada telinga, serta mempunyai riwayat terpapar suara bising.

Data yang dikumpulkan berupa usia, jenis kelamin, hasil audiometri nada murni sebelum pemberian terapi TB MDR, dan hasil audiometri nada murni selama pemberian TB MDR, serta keluhan yang timbul berupa tinitus, pendengaran berkurang, dan vertigo. Selain itu, onset timbulnya keluhan tersebut dan mulai terjadi perubahan audiogram selama terapi TB MDR.

\section{HASIL}

Selama periode 1 Januari - 31 Desember 2013, didapatkan 127 pasien penderita TB MDR yang telah mendapatkan terapi TB MDR. Dari 127 pasien didapatkan 26 pasien yang tidak datang kontrol (berobat dan tidak minum obat 2 bulan berturut-turut atau lebih sebelum masa pengobatan selesai) dan 15 pasien meninggal dengan berbagai sebab apapun, sehingga hanya 86 pasien yang dapat diambil datanya dengan lengkap.

Dari 86 pasien yang mendapat terapi TB MDR, didapatkan 72 pasien dengan hasil audiometri nada murni normal sebelum memulai terapi TB MDR. Selama terapi TB MDR didapatkan perubahan pendengaran pada 15 pasien $(20,8 \%)$, yaitu 14 pasien dengan hasil audiogram normal dan 1 pasien dengan hasil audiogram SNHL derajat ringan (tabel 2).

Tabel 3 menunjukkan bahwa keluhan yang sering dikeluhkan penderita adalah tinitus 7 pasien (46,6\%), gangguan dengar 4 pasien $(26,7 \%)$, dan tinitus disertai gangguan dengar 4 pasien (26,7\%). Tidak ada satupun pasien mengeluh adanya vertigo atau pusing berputar. Keluhan mulai dirasakan penderita paling banyak pada bulan ke-3 (53,3\%) 
setelah mulai pemberian terapi TB MDR, kemudian bulan ke-6 (40\%), dan bulan ke-10 $(6,7 \%)$ setelah pemberian terapi TB MDR. Pada saat timbul keluhan dilakukan audiometri nada murni dan telah ditemukan penurunan pendengaran sensorineural yang bervariasi dari derajat ringan sampai berat.

Tabel 1. Karakteristik pasien $(\mathbf{n}=\mathbf{8 6})$

\begin{tabular}{lrc}
\hline & $\mathrm{n}^{*}$ & $\%$ \\
\hline Jenis kelamin & & \\
Laki-laki & 52 & 60,5 \\
Perempuan & 34 & 39,5 \\
Usia & & \\
$<20$ & 3 & \\
$20-30$ & 20 & 3,5 \\
$31-40$ & 27 & 23,2 \\
$41-50$ & 22 & 31,4 \\
$>50$ & 14 & 25,6 \\
Rerata & 37,6 & 16,3 \\
Rentang & $15-64$ & \\
\hline
\end{tabular}

$\mathrm{n}^{*}$ : jumlah penderita TB MDR

Tabel 2. Hasil audiometri nada murni sebelum terapi TB MDR (baseline)

\begin{tabular}{cccccccccc}
\hline & \multicolumn{2}{c}{ Normal } & \multicolumn{2}{c}{ CHL } & \multicolumn{2}{c}{ SNHL } & \multicolumn{2}{c}{ MHL } \\
\cline { 2 - 10 } ADS & $\mathrm{n}$ & $\%$ & $\mathrm{n}$ & $\%$ & $\mathrm{n}$ & $\%$ & $\mathrm{n}$ & $\%$ \\
\hline
\end{tabular}

ADS: Auris Dextra Sinistra, CHL: Conductive Hearing Loss, SNHL: Sensorineural Hearing Loss, MHL: Mixed Hearing Loss

Tabel 3. Keluhan dan hasil audiometri nada murni selama terapi TB MDR

\begin{tabular}{|c|c|c|c|c|c|c|}
\hline & \multirow{2}{*}{ Jenis keluhan } & \multirow{2}{*}{$\begin{array}{l}\text { Onset } \\
\text { timbul } \\
\text { keluhan } \\
\text { bulan ke- }\end{array}$} & \multicolumn{2}{|c|}{$\begin{array}{c}\text { Hasil audiogram nada murni } \\
\text { baseline }\end{array}$} & \multicolumn{2}{|c|}{$\begin{array}{c}\text { Hasil audiogram nada murni } \\
\text { saat terapi }\end{array}$} \\
\hline & & & $\mathrm{AD}$ & AS & $\mathrm{AD}$ & AS \\
\hline 1 & Tinitus & 3 & Normal & Normal & SNHL ringan & SNHL ringan \\
\hline 2 & Tinitus & 10 & Normal & Normal & SNHL ringan & SNHL ringan \\
\hline 3 & $\begin{array}{l}\text { Tinitus, gangguan } \\
\text { dengar }\end{array}$ & 6 & Normal & Normal & SNHL sedang & SNHL ringan \\
\hline 4 & Tinitus & 3 & Normal & Normal & SNHL ringan & SNHL ringan \\
\hline 5 & Tinitus & 3 & Normal & Normal & SNHL ringan & SNHL ringan \\
\hline 6 & $\begin{array}{l}\text { Tinitus, gangguan } \\
\text { dengar }\end{array}$ & 6 & Normal & Normal & SNHL berat & SNHL berat \\
\hline 7 & Tinitus & 3 & Normal & Normal & SNHL ringan & SNHL ringan \\
\hline 8 & Gangguan dengar & 6 & SNHL ringan & SNHL ringan & SNHL sedang & SNHL sedang \\
\hline 9 & Tinitus & 6 & Normal & Normal & SNHL ringan & SNHL ringan \\
\hline 10 & Gangguan dengar & 3 & Normal & Normal & SNHL ringan & SNHL ringan \\
\hline 11 & Gangguan dengar & 3 & Normal & Normal & SNHL ringan & Normal \\
\hline 12 & $\begin{array}{l}\text { Tinitus, gangguan } \\
\text { dengar }\end{array}$ & 6 & Normal & Normal & SNHL sedang & SNHL sedang \\
\hline 13 & Gangguan dengar & 3 & Normal & Normal & Normal & SNHL ringan \\
\hline 14 & Tinitus & 3 & Normal & Normal & SNHL ringan & SNHL ringan \\
\hline 15 & $\begin{array}{l}\text { Tinitus, gangguan } \\
\text { dengar }\end{array}$ & 6 & Normal & Normal & SNHL berat & SNHL sedang \\
\hline
\end{tabular}




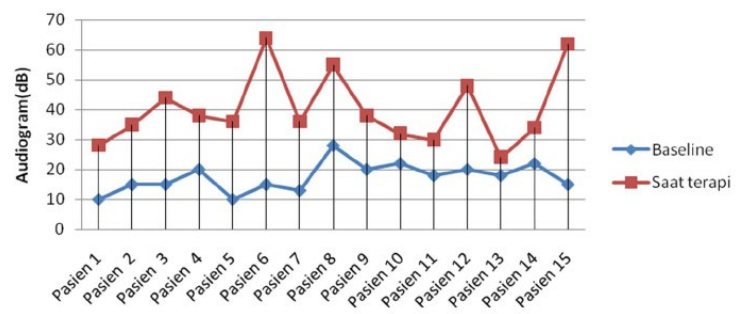

Gambar 1. Audiogram baseline dan saat terapi TB MDR pada telinga kanan

\section{DISKUSI}

Hasil penelitian ini menunjukkan bahwa penderita TB MDR periode 1 Januari-31 Desember 2013 lebih banyak pada laki-laki dibandingkan perempuan. Hal ini sesuai dengan penelitian yang dilaporkan oleh Duggal $^{3}$ dan Rafique ${ }^{9}$ namun hal ini tidak sesuai dengan yang dilaporkan penelitipeneliti lain seperti Reviono. ${ }^{10}$ Perbedaan ini kemungkinan disebabkan oleh jumlah subjek penelitian yang diteliti tidak sama dan tidak ada hubungan langsung antara insidens penderita TB MDR dengan jenis kelamin. Berdasarkan usia, hasil penelitian menunjukkan penderita terbanyak pada usia 31-40 tahun dan sebagian besar subjek penelitian merupakan usia produktif, kemungkinan karena aktivitasnya yang lebih tinggi dibandingkan kelompok usia yang lain.

Terapi aminoglikosida pada TB MDR berisiko untuk terjadinya gangguan fungsi ginjal, fungsi telinga, dan sistem keseimbangan. Gangguan fungsi ginjal bersifat reversible akan tetapi gangguan pendengaran dan sistem keseimbangan tubuh bersifat irreversible atau permanen. Kerusakan pada koklea dapat menimbulkan penurunan pendengaran permanen. ${ }^{8}$

Mekanisme awal aminoglikosida dalam merusak pendengaran adalah penghancuran sel-sel rambut koklea, khususnya selsel rambut luar. Aminoglikosida muncul untuk menghasilkan radikal bebas di dalam telinga bagian dalam dengan mengaktifkan nitric oxyde sintetase (NOS) yang dapat

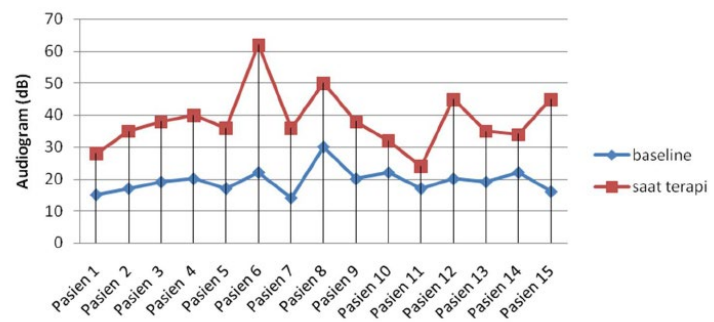

Gambar 2. Audiogram baseline dan saat terapi TB MDR pada telinga kiri

meningkatkan konsentrasi oksida nitrat membentuk radikal peroksinitrit destruktif yang dapat secara langsung merangsang kematian sel. Apoptosis adalah mekanisme utama kematian sel dan terutama diperantarai oleh kaskade mitokondria intrinsik. Fenomena ini menyebabkan kerusakan permanen pada sel-sel rambut luar koklea, yang mengakibatkan kehilangan pendengaran permanen. ${ }^{8}$

Dari 86 pasien yang mendapat terapi TB MDR, didapatkan 72 pasien dengan hasil audiometri nada murni normal sebelum memulai terapi TB MDR. Selama mendapat terapi TB MDR didapatkan 15 pasien (20,8\%) mengeluhkan tinitus ataupun penurunan pendengaran yang dibuktikan dengan hasil pemeriksaan audiometri nada murni.

Kejadian awal ototoksik yang disebabkan oleh obat golongan aminoglikosida berdampak pada frekuensi tinggi $(>4000 \mathrm{~Hz})$. Hal ini dapat diketahui melalui pemeriksaan audiometri nada murni dan pasien tidak akan merasakan keluhan. Pada keadaan yang lanjut, frekuensi percakapan telah terganggu maka penderita akan mulai merasakan keluhan dan kerusakan yang terjadi telah bersifat irreversible. ${ }^{2,11}$

Penelitian yang dilakukan di Afrika Selatan oleh Khoza-Shangase et al ${ }^{11}$ menyebutkan bahwa didapatkan gangguan pendengaran frekuensi tinggi pada skrining penderita TB MDR. Pada penelitian itu juga disebutkan bahwa penderita MDR TB dengan gangguan dengar pada frekuensi tinggi tidak 
memberikan gejala klinis. Namun, kerusakan ini akan terus berlanjut sehingga pada akhirnya akan terjadi kerusakan yang lebih luas dan bersifat irreversible dan memberikan gejala klinis.

Gangguan pendengaran karena pemberian aminoglikosida biasanya terjadi setelah 3 sampai 4 hari, tetapi dapat terjadi segera setelah dosis pertama. Gangguan dengar yang permanen dapat tertunda dalam hitungan hari, minggu, ataupun bulan setelah selesai terapi. Gangguan pendengaran bilateral mendominasi, namun tidak jarang pula ditemukan unilateral. ${ }^{8}$

Pada penelitian ini keluhan yang sering dilaporkan penderita adalah tinitus 7 pasien $(46,6 \%)$, gangguan dengar 4 pasien $(26,7 \%)$, dan tinitus disertai gangguan dengar 4 pasien (26,7\%). Tidak ada satu pun pasien mengeluh adanya vertigo atau pusing berputar. Keluhan mulai dirasakan penderita paling banyak pada bulan ke-3 $(53,3 \%)$ setelah mulai pemberian terapi TB MDR, kemudian bulan ke-6 (40\%), dan bulan ke-10 (6,7\%). Pada saat timbul keluhan dilakukan audiometri nada murni dan telah ditemukan penurunan pendengaran sensorineural yang bervariasi dari derajat ringan sampai berat.

Kehilangan pendengaran atau gangguan keseimbangan yang permanen disebabkan oleh obat ototoksik mungkin memiliki dampak pada komunikasi, edukasi, dan sosial yang serius. Oleh karena itu harus dipertimbangkan apakah keuntungan pemakaian obat lebih banyak daripada kerugiannya. Penanganan ditekankan pada pencegahan karena sebagian besar kehilangan pendengaran bersifat irreversible. Saat ini tidak terdapat terapi untuk menyembuhkan kerusakan akibat obatobatan ototoksik, akan tetapi peneliti dan klinisi mencoba untuk menemukan metode baru untuk meminimalkan cedera ototoksik, salah satunya dengan monitoring fungsi pendengaran. ${ }^{6}$
Monitoring fungsi pendengaran pada ototoksisitas memiliki dua tujuan utama yaitu deteksi dini gangguan pendengaran serta intervensi fungsi pendengaran jika sudah timbul gangguan pendengaran. Bila tujuan utama monitoring fungsi pendengaran sudah tercapai maka dapat dilakukan tujuan berikutnya yaitu penatalaksanaan gangguan dengar yang tidak dapat diobati secara medikamentosa, seperti konseling, strategi komunikasi, dan amplifikasi atau pemakaian alat bantu dengar. ${ }^{12}$ Deteksi dini gangguan pendengaran akibat obat ototoksik memberikan kesempatan kepada dokter untuk mengevaluasi pemberian terapi dalam meminimalkan atau mencegah gangguan pendengaran yang membutuhkan rehabilitasi. ${ }^{3}$

Tiga pendekatan utama untuk monitoring fungsi pendengaran pada ototoksisitas yaitu audiometri nada murni, audiometri frekuensi tinggi (HFA), dan emisi otoakustik (OAE). Seluruh pendekatan tersebut dapat digunakan secara terpisah atau kombinasi. ${ }^{12}$

Evaluasi atau monitoring fungsi pendengaran pada penggunaan aminoglikosida sebaiknya dilakukan seminggu atau 2 minggu sekali. Monitoring dapat dilanjutkan walaupun penggunaannya telah dihentikan karena aminoglikosida dapat menyebabkan gangguan pendengaran yang tertunda sampai beberapa bulan setelah pengobatan dihentikan. ${ }^{12}$

Dari hasil penelitian terhadap pasien yang mendapat terapi TB MDR di poliklinik TB MDR RS Hasan Sadikin Bandung periode 1 Januari-31 Desember 2013 didapatkan gangguan pendengaran sebanyak 20,8\% dari pasien TB MDR selama mendapat terapi TB MDR dengan keluhan tinitus dan gangguan pendengaran dengan onset timbulnya keluhan di bulan ke-3 $(53,3 \%)$ setelah mulai pemberian terapi TB MDR, kemudian bulan ke-6 (40\%) dan bulan ke-10 (6,7\%). Pada saat timbul keluhan dilakukan audiometri nada murni dan telah ditemukan penurunan pendengaran sensorineural yang bervariasi dari derajat ringan sampai berat. 
Pengobatan TB MDR yang menggunakan aminoglikosida dapat menyebabkan penurunan pendengaran sensorineural. Pemberian aminoglikosida tidak bisa dihentikan pada individu dengan TB MDR. Namun, terdapat beberapa strategi yang dapat dilakukan untuk mengurangi tingkat gangguan pendengaran pada pasien tersebut, yaitu dengan melakukan suatu monitoring fungsi pendengaran.

\section{DAFTAR PUSTAKA}

1. World Health Organization. Key point. WHO report: Global tuberculosis control 2012 surveillance, planning, financing. Geneva: WHO, 2012.

2. World Health Organization. Guidelines for management of drug resistant tuberculosis. Geneva: WHO, 2011.

3. Duggal P, Sarkar M. Audiologic monitoring of multi-drug resistant tuberculosis patients on aminoglycoside treatment with long term follow-up. BMC Ear Nose and Throat Disord. 2007; 7: 5.

4. Anonim. Pengendalian TB resisten obat. Sub Direktorat Tuberkulosis. Direktorat Jenderal Pengendalian Penyakit dan Penyehatan Lingkungan. Jakarta: Depkes RI, 2011.

5. Schuman RM. Ototoxicity. In: Bailey BJ. Head \& Neck Surgery - Otolaryngology, $4^{\text {th }}$ edition. Chapter 148. New York : Lippincott Williams \& Wilkins, 2006. p465.
6. Mudd, PA. Inner Ear, Ototoxicity. (cited May 7, 2012). Available from : http:// emedicine.medscape.com/article/857679overview.

7. Anonim. Ototoxicity. (cited August, 2013). Available from : www.vestibular. org. 2011.

8. Stringer SP, Meyerhoff WL, Wright CG. Ototoxicity. In: Paparella MM, Shumrick DA, Gluckman JL, Meyerhoff WL, editors. Otolaryngology. Third Edition. Philadelphia: W.B. Saunders Company, 1991. p.1653.

9. Rafique A, Dastgir M, et al. Streptomycin associated hearing loss in patients treated for multidrug resistant tuberculosis. Isra Med Journal. 2012; (4);139-42.

10. Reviono, Widayanto, Harsini, Aphridasari J, Sutanto YS. Streptomisin dan insidens penurunan pendengaran pada pasien Multidrug Resistant Tuberculosis di Rumah Sakit Dr. Moewardi. Surakarta. J Respir Indo. 2013; 33(3); 167-172.

11. Khatijah Khoza-Shangase, Anniah Mupawose. 2009. Ototoxic effects of tuberculosis treatments: how aware are patients. African Journal of Pharmacy and Pharmacology. 2009; 3(8); 391-399.

12. Durrant JD, Campbell K, Fausti S. American Academy of Audiology Position Statement and Clinical Practice Guidelines : Ototoxicity Monitoring. Wahington: American Academiy of Audiology; 2009. 